\title{
EL DICCIONARIO ALEMÁN-TARAHUMARA DE MATTHÄUS STEFFEL Y LA TIPOLOGÍA LINGÜÍSTICA DEL SIGLO XVIII
}

\section{The German-Tarahumaran dictionary of Matthäus Steffel and the linguistic tipology of the 18th Century}

Aarón Grageda ${ }^{1}$

Fecha de recepción: 11 de octubre del 2017

Fecha de aceptación: 26 de noviembre del 2017

1- Nacionalidad: Mexicana. Grado: Doctorado. Especialización: Historia. Adscripción: Universidad de Sonora. Correo electrónico: agrageda@sociales.uson.mx. ORCID: http://orcid.org/0000-0003-1031-1841 


\section{Resumen}

La presente contribución analiza el contexto de surgimiento de un diccionario bilingüe alemán-tarahumara, escrito el siglo XVIII por un misionero moravo, Matthäus Steffel. Se indaga su lugar como esfuerzo emprendido en la Europa ilustrada, para organizar las diferentes lenguas del mundo de acuerdo con su parentesco. La elaboración del diccionario, relativo a una lengua nativa del norte de la Nueva España, es vista aquí en el horizonte de la colaboración entre letrados de la época interesados en la lingüística. Ello hizo posible la recolección, crítica y publicación de información con contenido lingüístico que alentaría, sobre todo en el espacio cultural de habla alemana, la formación del campo emergente de los estudios lingüístico-tipológicos.

Palabras clave: Ilustración, tarahumara, diccionario, Steffel, tipología.

\section{Abstract}

This contribution focuses on a German-Tarahumaran dictionary elaborated in the 18th century by the Moravian missionary Matthäus Steffel and investigates this text as part of the European Enlightment effort to organize the various languages of the world regarding their kinship relation. As is shown, the elaboration of the dictionary, dedicated to an ethnic group of Northern New Spain, has to be seen in the context of broader cientific colaboration common within linguistic studies of the epoque. This colaborative approach made possible the recollection, critique and publication of linguistic information which would, especially in the German speaking countries, lead to the emergence of typological studies.

Keywords: Enlightenment, Tarahumara, dictionary, Steffel, tipology. 


\section{Introducción: la lingüística europea a finales del XVIII y el diccionario tarahumara}

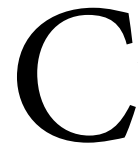
ontribuciones historiográficas relevantes, dedicadas a explicar las formas de comunicación establecidas entre Europa y el resto del mundo durante la etapa previa a la Revolución Industrial; así como otras dedicadas a entender cómo se efectuó el intercambio de información entre el Viejo Continente y las geografías y grupos humanos hasta entonces poco conocidos, sostienen que "entre 1780 y 1914 el mundo se volvió más uniforme a la vez que más internamente diferenciado" (Bayly, 2004: 21). En cuanto a los aspectos lingüísticos de dicha diferenciación, según afirma Jürgen Osterhammel, las comunidades letradas de la época se dedicaron por entonces a recabar documentos por doquier, de tal modo que "muchos académicos reunieron informaciones y objetos de distintas partes del mundo; estudiaron las lenguas, las costumbres y las religiones de los más remotos pueblos" (2014: XV).

Si se pone atención a la relación existente entre las lenguas del mundo, y en particular a los esfuerzos que se realizaron en el universo cultural de lengua alemana, la segunda mitad del siglo XVIII resulta ser un periodo excepcional para explicar las estrategias empleadas para establecer relaciones de parentesco entre lenguas vivas en distintas regiones del mundo.

Si bien el presente artículo se centra a observar dicho espacio cultural, no se deja de lado contribuciones intelectuales significativas surgidas en otros ámbitos, como los de habla inglesa, francesa y española, donde existieron en la época distinguidos tratadistas y eruditos interesados por igual en indagar el origen y la relación existente entre las distintas lenguas con las que establecían contacto. En el estudio de las lenguas, destacan en un primer momento filósofos de la talla de Adam Smith, Locke, Condillac, Ferguson, Maupertius, Foster y Rousseau, quienes en una temprana etapa, y no sin esforzados intentos de sistematicidad, ofrecieron interpretaciones en torno al origen de las diversas lenguas del mundo (Aarsleff 1974; Salmon 1996: 184; Gascoine 2003: 162 y Kendon 2013: 74). Es importante hacer mención de ello, para delimitar la interrogante en torno al surgimiento y utilidad que tuvo un breve diccionario bilingüe que describe vocablos de una lengua originaria del norte de la Nueva España (hoy México), la lengua de los rarámuri o tarahumaras, y el lugar que ocupará esta obra en los esfuerzos tipológicos realizados por entonces.

En el ánimo de complementar significativas aportaciones previas (Merrill, 2007; Brumm, 2007; Kř́žová, 2013), la presente contribución ofrece datos e interpretaciones no abordados que permiten, no sólo conocer con mayor exactitud las condiciones preexistentes a la publicación del diccionario alemántarahumara, sino sobre todo introducir una nueva hipótesis, relativa a su empleo en la etapa inicial del surgimiento de la tipología germana, aspecto a lo cual contribuyó, de manera consiente o indirecta, la elaboración de dicho recurso lexicográfico por Matthäus Steffel. Del mismo modo, se documentan las repercusiones que la obra de este misionero, enviado por la Compañía de Jesús a evangelizar las regiones ignotas del septentrión novohispano, tuvieron al iniciar la década de los sesenta del siglo XVIII (Hausberger, 1995: 35). Después de dos estudios previos que elaboró de la lengua tarahumara, los cuales no tuvieron la fortuna de llegar a imprenta, ${ }^{2}$ el diccionario bilingüe fue publicado por primera y única

2- Se hace referencia al ubicado en Archiv města Brna, localizado en la ciudad de Brno, República Checa, intitulado "Grammatica Linguæ Tarahumaricæ Americanæ nationis in regno Novæ Viscayæ [...] Brunæ Moravorum 1799”; así como a un segundo manuscrito, mismo que se encuentra en el Moravský zemský Archiv, también en Brno, que contiene el "Tarahumarisches Wörterbuch". 
ocasión en la ciudad de Halle an der Saale, Alemania, en 1809, por el editor Johann Christian Handel, como parte de una compilación mayor de textos relativos a las regiones americanas donde los jesuitas habían llevado a cabo su labor catequética.

\section{Otro jesuita en la Tarahumara Alta}

El Tarahumarisches Wörterbuch, como se le conoció en alemán, está constituido por ochenta y cuatro páginas y tiene como obra lexicográfica una estructura clásica como diccionario bilingüe (Díaz, 2010). La hoja que le sirve de portada interna contiene el nombre del autor y el título del diccionario. En ella se consigna: Tarahumarifches Wörterbuch, nebft einigen Nachrichten von den Sitten und Gebraeuchen der Tarahumaren, in Neu-Bifcaya, in der Audiencia Guadalaxara im Vice-Koenigreiche Alt-Mexico, oder Neu-Spanien.

El diccionario es el segundo escrito en la compilación de textos que se incluye en un libro de relaciones sobre el Nuevo Mundo, del cual se dará cuenta a detalle más adelante. Baste señalar por ahora, que el diccionario comprende de la página 301 a la 374, abarcando también un anexo o "Anhang", intitulado: "Von der tarahumarischen Art zu zählen", o de la forma de contar de los tarahumaras. ${ }^{3 *}$ En la página $295^{4}$, se da inicio a la introducción del opúsculo, que se transforma a la vez en contenido de una dedicatoria al lector, signada con el nombre del misionero. En ella se hace alusión a la definición del alfabeto tarahumara y a la situación de que su autor, Steffel, reúne por ese entonces mas de 20 años de no tener contacto con los hablantes de la lengua, consignando seguidamente la fecha de culminación del manuscrito original, el 28 de marzo de 1791.

Queda como tarea de la investigación histórica indagar con qué recursos documentales, notas o escritos particulares logró Steffel elaborar su diccionario después de tantos años de no tener el uso regular de la lengua, sobre todo si consideramos que desde su expulsión a la conclusión del manuscrito transcurrirían veinticuatro años. Baste señalar que cuando se publica el diccionario, en 1809, el misionero no se encontraba ya con vida y habían pasado por lo menos dieciocho años desde que había entregado el borrador a quien sería su editor, para que éste lo diera a imprenta.

Se conoce, por declaraciones emitidas por otros miembros de la orden, que al efectuarse la expulsión de los misioneros de los reinos de ultramar, la autoridad monárquica fue exhaustiva en el control de sus posesiones y de los objetos personales que transportaban. Joseph Och, jesuita de la región vecina conocida como Pimería (y quien regresa a Europa en el mismo contingente en que se encontraba Steffel), lamenta por ejemplo que fue despojado de sus múltiples escritos, llegando a Europa sin sus apuntes y libros personales (Och, 1809: 80).

Steffel arribó a la Tarahumara hacia 1761. Los datos históricos que se han ofrecido hasta hoy (Merrill, 2007: 435), confirman su presencia en la denominada Tarahumara Alta, particularmente en poblaciones como las de Tonáchic, así como posteriormente en Tomóchic, Yepáchic, Tutuaca, Nonoaba y San Borja; lo anterior, hasta 1766, un año antes de que se ordenara por Carlos III, que los jesuitas abandonaran las misiones del Nuevo Mundo.

3- * Traducción libre por Aarón Grageda Bustamante.

4- Por error en la numeración aparece 395, después de esta página la numeración se restablece correctamente. 
Ahora bien, basados en el registro histórico de su presencia en la zona, se podría afirmar que el contacto de Steffel con la lengua tarahumara no duró más de seis años y con seguridad, debido a las enormes distancias que yacen entre las poblaciones mencionadas, pudo haber tenido conocimiento de variaciones dialectales que por razones que desconocemos no menciona a profundidad en su diccionario.

Volviendo de nuevo a la descripción física de la que llegará a ser su única obra impresa, podemos afirmar que de la cuarta a la octava página del diccionario (296-300), Steffel presenta un estudio preliminar (o Vorbericht), firmado como nota de autor (Verfasser). Por lo personal de las experiencias que se narran, así como por las indicaciones que se introducen acerca de la lengua, puede asumirse que éstas proceden efectivamente del misionero moravo. Inmediatamente después, se da paso a las entradas propiamente dichas, las cuales se dividen en dos partes específicas; primero la sección más extensa, la alemana-tarahumara, seguida de la correspondiente al tarahumara-alemán que es mucho más breve en la extensión y contenidos de sus campos.

En la parte que podemos considerar final, el diccionario incluye un apartado de oraciones en latín, seguidas por sus traducciones en tarahumara y alemán, para que estas pudieran servir de recurso informativo a quienes, como veremos, estuvieran interesados en emplearlas con fines gramaticales o de comparación. Se incluye, como afirmamos en un inicio, un "anexo" con la forma de contar de los tarahumaras y la traducción de un párrafo en dicha lengua, correspondiente al "Padrenuestro", mismo que retomaremos más adelante, con el fin de exponer el uso que el diccionario tuvo entre letrados posteriores. Por limitaciones de espacio, es imposible hablar en esta contribución del significativo aporte lingüístico del diccionario y lo que éste representa como recurso para indagar la evolución y variaciones de la lengua; baste destacar que algo de ello ha sido ofrecido ya en otras publicaciones (Estrada Fernández y Grageda Bustamante, 2013: 188).

Ahora bien, la calidad enciclopédica de las entradas del diccionario y la manera como el autor desarrolla diversas descripciones sobre usos y costumbres, herencia material y cultural de dicha población americana originaria, ha llevado a considerar a Matthäus Steffel como digno precursor de estudios antropológicos en la Nueva España (Brenscheidt, 2014). En un sentido semejante, complementando estudios previos, que afirman que el diccionario de Steffel tuvo una finalidad predominantemente práctica (González Rodríguez 1993), la presente contribución propone como hipótesis, que la singular riqueza de dicha obra, además de constituir un instrumento lingüístico de gran valor, fue también utilizada como insumo informativo para los esfuerzos de quienes por entonces trabajaban en clasificar las lenguas de la época. Lo anterior no excluye el hecho, de que al momento de elaborar su diccionario, el misionero vio en él la oportunidad de enmendar la gran obra lingüística previa sobre dicha lengua; a saber, la Gramática de la lengua tarahumara y guazapar, publicada por su predecesor y correligionario, el padre jesuita Thomas de Guadalaxara, en $1683^{5}$.

Si se atiende al contexto de su impresión y circulación, el diccionario resulta ser una obra única entre las producidas durante la etapa novohispana: como tal, el Tarahumarisches Wörterbuch es el único diccionario o vocabulario que habiendo sido escrito por un misionero, se llevó a cabo sin el concurso de la

5- En torno a la vida de este misionero jesuita y su residencia en la Tarahumara véase el artículo intitulado: “Thomas de Guadalaxara (1648-1720), misionero de la Tarahumara, historiador, lingüista y pacificador” (González, 1995). En lo concerniente a su aportación lingüística consultar la edición preparada por Abel Rodríguez López (2010), que cuenta con un importante aparato crítico. 
Iglesia; así como tampoco nunca contó con una finalidad catequética. El diccionario posee un espíritu ilustrado, visible en la fascinación que muestra su autor por los hábitos y destrezas de los naturales, por sus bailes, comidas y bebidas, así como por la detallada descripción que realiza en sus entradas respecto a su forma de vida, su posesión material y su entorno. ${ }^{6}$

William W. Merrill (2007), quien ha dedicado gran parte de su labor investigadora al análisis del contenido y riqueza de la obra de Steffel, ha subrayado el valor que éste posee como fuente para la preservación cultural de dicho grupo étnico (413). Destaca además la importancia que reviste el trabajo que este misionero emprendió, para conocer hoy la evolución de la lengua; gracias a "el sumo cuidado con el que [el jesuita] documentó las palabras tarahumaras". Señala a su vez que gozando el autor del diccionario de "buen oído" para los idiomas, "evitó estandarizar las formas del tarahumara", ya que éste documenta "pronunciaciones alternativas para la misma palabra e incluyó un gran número de formas irregulares, ambos aspectos cruciales para entender la complejidad y dinamismo del idioma”. Además, agrega que el detallado registro que llevó a cabo este religioso en su diccionario, puede considerarse "un sustento sólido para investigar tanto las constantes como los cambios [de la lengua] durante los últimos doscientos años" (416).

Una vez expuesta de forma sucinta la forma, contenido y riqueza del diccionario, su espíritu enciclopédico y su condición de recurso etnográfico, se procederá en los apartados subsiguientes a desarrollar el escenario internacional, relativo al contexto lingüístico e intelectual que dio vida al mismo. Como se verá a continuación, dicha obra permite trascender la tarea de emplearlo como un instrumento lexicográfico más, haciendo posible abordar su uso como evidencia de debates que por entonces ocupaban a los lingüistas de la época. Se busca explicar de esta manera, la dimensión global en la que diccionario tarahumara-alemán fue utilizado como evidencia material, para rastrear el origen y el posible agrupamiento general de las lenguas americanas.

$\mathrm{Al}$ esclarecerse dicha función, se espera explicar por qué el jesuita se dio a la tarea de sacar a la luz su diccionario después de tantos años, a pesar de vivir tanto tiempo retirado de la misión a la que dedicó su empeño evangélico y donde, como consigna en su propio diccionario, siempre anheló regresar. De esta forma se podrá responder la interrogante planteada por el propio misionero en la presentación de su obra, en la que se pregunta: “¿Quién encontrará utilidad a este esfuerzo mío?” (Steffel, 1809: 297).

\section{Sobre la idea de una clasificación universal de las lenguas}

En cuanto al origen de la diversidad de las lenguas humanas, es conocido cómo intelectuales alemanes, entre los que destacaron Süßmilch y Herder, ensayaron sus interpretaciones relativas al carácter -ora divino, ora humano-, de la diversidad de las lenguas del mundo. Ambos estudiosos propusieron respuestas, apoyados sobre todo en la filosofía y en la historia (Carhart, 2007: 90; Lifschitz, 2012: 26). Si para el primero, la complejidad de las lenguas era resultado divino, al sobrepasar esto el ingenio y las

6- Vid. 'Mädchen” o 'Muchacha' como entrada en el Tarahumarisches Wörterbuch. En ella describe Steffel la correspondencia tarahumara como 'Teguéke', y define: “Entre tarahumaras es costumbre general trazar figuras en el rostro de sus hijitas. Con una espina oradan sus frentes dibujando culebrillas con puntos, sobre los labios una escalera y en ambas mejillas una ruedita con rayas erguidas. Estos agujeros son tallados con fino polvo de carbón y permanecen indelebles. Les da un aspecto horroroso. Para que el lector también identifique en esta ruda nación, la tendencia que tienen sus mujeres a la limpieza, agrego que las tarahumaras sirven de pintarse con un ungüento rojo, con el que se embadurnan las mejillas". (1809: 330) 
posibilidades intelectivas dadas por Dios al hombre; la variedad de lenguas representaba para el segundo la evidencia definitiva de que ello no podía ser sino creación humana, reafirmando así la superioridad expresiva del hombre respecto a los demás seres de la creación.

En el espacio cultural de habla alemana, al que limitamos la presente aportación, la pregunta sobre el origen de las lenguas abrió paso a otra cuestión no menos escabrosa (y en cierta medida más difícil de responder por la amplitud temática que representaba); a saber, cómo puede elaborarse una clasificación racional y metódicamente correcta de las diferentes lenguas del mundo. A finales del siglo XVIII, dicha pregunta tornará la especulación lingüística de corte filosófico (característica de la etapa inicial de la Ilustración) y la volcará en definitiva al sprit géometrique propio de la época (Frängsmyr, Heilbron y Rider, 1990: 2). Así como sucedió en las ciencias exactas con la medición terrestre y el calculo, se muestran a continuación ejemplos tempranos de esta pasión por ordenar y sistematizar las lenguas del mundo, algo que demandó la documentación correspondiente.

Se ha propuesto, que las reflexiones de G. W. Leibniz (1646-1716) representan, no sólo uno de los primeros "trabajos característicos de la reflexión lingüística del período ilustrado" (Gardt, 1999: 194), sino que constituyeron un ejercicio pionero, encaminado a principios del XVIII, a la tarea de enmarcar las lenguas y sus grupos en categorías. Debe sin embargo señalarse, que eruditos de esa época como Leibniz se abocaban al estudio de las lenguas euroasiáticas y que dicho esfuerzo lo realizaron con apego a la genealogía, a la filosofía y a la historia. Un "espíritu más moderno" partió del entendimiento de las lenguas como provenientes de un mismo origen común, dividiéndolas posteriormente en dos grupos, las jaféticas y las araméicas. Pedersen ha propuesto, dada la simplicidad de ese nivel de síntesis, que las contribuciones a la tipología lingüística de esa época "provenían más de la intuición que de la creación de conocimiento" (1983: 33).

Originados en un espacio cultural distinto, los intentos de especulación clasificatoria de Leibniz se verán complementados por la documentación lingüística que fue reunida en los ocho volúmenes de Of the Origin and Progress of Language (1773-1793) y la Ancient Metaphysics (1777-1799), publicados por James Brunett (1714-1799). Asimismo, en torno al tema de la clasificación de las lenguas, se reconoce en Brunett el desarrollo de una temprana "perspectiva evolutiva" y la seguridad de que existía, según él, cierta familiaridad entre las lenguas antiguas y las modernas (Plank, 2001: 1412). Dicho letrado, en su labor, ordenó cerca de cincuenta lenguas, entre las que se incluyeron algunas americanas, como la de los grupos caribes y hurones.

En este mismo horizonte temporal, otro ejercicio de compilación lingüística marcará los esfuerzos europeos por establecer una tipología confiable y sistemática, éste será desarrollado por Bacmeister, un iniciado en el tema. Con él se realizará un intento por sentar las bases, no sólo de la fundamentación clasificatoria al interior de la tradición lingüística, sino también introducir lo que a la postre será una de sus disciplinas más importantes; a saber, los estudios lingüístico-comparativos.

\section{Litterati et lumières}

Una cadena de intercambios entre eruditos europeos del siglo XVIII, interesados lo mismo en la literatura que en la descripción de los pueblos y las culturas del mundo, permite rastrear los primeros intentos de reflexión tipológica, inspirados por procesos sistemáticos de recolección de información lingüística. Ellos no excluyeron en la época la recopilación de lenguas centro y sudamericanas. El primer eslabón de 
un caso particular, comprende el interés por conocer la lengua y hablantes del tarahumara, población ubicada en la Sierra Madre Occidental, al norte de la Nueva España; nos referimos al carteo iniciado por el letrado y súbdito prusiano Christoph Gottlieb von Murr (1733-1811).

A la par de los importantes estudios literarios y bibliográficos que llevó a cabo, donde dejó rastro de sus inquietudes intelectuales, así como de datos que permiten reconstruir su vida y formación académica, puede agregarse que von Murr se desempeñó en la época como editor, reforzando vínculos intelectuales que lo llevaron a cartearse, lo mismo con filósofos que con viajeros o filósofos ilustrados, poseedores de una amplia producción literaria (Borja 2011: 220; Jürgensen 2002: 1311). Junto a ello, resulta necesario apuntalar otras relaciones que explican su pasión e interés por la diversidad lingüística.

Christoph Gottlieb von Murr fue originario de Núremberg, lugar donde, a decir de uno de sus biógrafos, cursó estudios como bachiller, adquiriendo una sólida formación en lenguas antiguas y contemporáneas, entre las que destacaron el hebreo, el francés y el latín (Mummenhoff 1886: 76). Junto a ello, cultivó además su formación en ciencias naturales, filosofía, matemáticas, arqueología e historia. Antes de concluir su habilitación doctoral en 1756, en la Universidad de Altdorf, dio muestra de la capacidad de sus deliberaciones académicas, interesándose especialmente por el proyecto de establecer una tipología lingüística universal.

En las descripciones que publicaba, von Murr solía dar cuenta de su vida y de los trabajos que realizaba, por ello se sabe que durante su cenit intelectual, declaró ser de confesión protestante, así como el haber ocupado un cargo como alto funcionario de aduanas en su ciudad natal. En dicha época presume haber sido miembro de Academias, donde destaca su aceptación como miembro del Real Instituto Histórico de Gotinga y de haber disfrutado salario como investigador en la Sociedad de Investigación Natural en Berlín (von Murr, 1774).

Entre los múltiples vínculos intelectuales que aún el día de hoy pueden corroborarse archivísticamente, destacan las relaciones epistolares que sostuvo, no sólo con ilustrados de la talla de Gotthold Ephraim Lessing, sino también con otros representantes de los campos literarios y humanísticos de lengua alemana. En este sentido, son significativas sus comunicaciones con Johann Gottfried von Herder (UM, 1788: 54), Johann Christoph Adelung (BS, 1796: 1) y Friedrich von Schiller (BS, 1794: 1). Más allá de Prusia, destaca por ejemplo su relación epistolar con el misionero franciscano, espeleólogo y naturalista español José Torrubia (SH, 1773: 1). No obstante, en el trato que sostiene con exponentes de diferentes confesiones, destaca el que mantiene con los misioneros de la Compañía de Jesús, con quienes cultiva una prolífica amistad, que le permitirá entre otras cosas allegarse la colaboración de Matthäus Steffel.

Producto de esa relación con los jesuitas, von Murr publica siete años después de emitido el decreto de expulsión de la Compañía, un libro intitulado Acht und zwanzig Briefe über die Aufhebung des Jesuitensordens (von Murr, 1774). Al parecer, llegó a ser tanta la información que reunió gracias a ellos (proveniente lo mismo de Sudamérica que de China), que de 1775 a 1789 se dio a la tarea de darlos a imprenta en una revista periódica titulada Journal zur Kunstgeschichte und zur allgemeinen Litteratur, aparecida en 17 tomos (von Murr, 1789). Tarea similar fue la dada a conocer posteriormente, llevando a publicación los años de 1778 y 1779, en dos tomos, el denominado Neues Journal zur Litteratur und Kunstgeschichte (von Murr, 1799).

Su biógrafo, que ha sido citado con antelación, señala que "las relaciones ampliamente ramificadas que von Murr tuvo con un gran número de eruditos, [así como] las relaciones que cultivó con jesuitas ilustrados, le resultaron en un gran servicio" (Mummenhoff, 1886: 78). 
En esa serie de publicaciones periódicas, von Murr dio salida impresa a mucha documentación sobre lenguas del mundo, que luego habrán de servir para fundamentar su arreglo e idea general de clasificación lingüística. Destacaron entre ellas las procedentes del nuevo continente, como las de Paraguay y de Brasil, aunque la proveniente de la Tarahumara será la que permitirá revelar la profunda dimensión de su relación con la comunidad intelectual europea, al igual que brindará peso específico a la discusión lingüística en torno a la tipología en la época.

Entre los esfuerzos de compilación lingüística de Christoph Gottlieb von Murr y la publicación del Tarahumarisches Wörterbuch de Matthäus Steffel se establece una extensa cadena de relaciones intelectuales, cuyo eslabón decisivo será Hartwig Ludwig Christian Bacmeister. El origen del vínculo entre von Murr y Bacmeister es decisivo respecto a la relación de intercambio documental que los esfuerzos tipológicos exigían a finales del siglo XVIII.

\section{La conexión Bacmeister}

Nacido en Herrnburg, Alemania, en 1730, Bacmeister fue otro de los ilustrados dedicados a las tareas de recolección de materiales lingüísticos (Lauch, 1969:24). Con estudios universitarios, tanto de historia como de jurisprudencia, partió junto con un grupo de ilustrados de la Universidad de Gotinga a desempeñarse como intelectual en la corte de Catalina II, en San Petersburgo, una vez iniciada la segunda mitad del siglo XVIII. Hacia 1772, Bacmeister declara ocupar por entonces el puesto de Inspector del Gymnasium der kayserlichen Akademie der Wissenschaften y ser miembro de la Königlische Deutsche Gesellschaft en Gotinga (Bacmeister, 1772). Desde ahí, comenzó a sistematizar la búsqueda de documentación sobre el reino de Rusia, a la vez que se dedicó a la escritura de la historia imperial de casa dinástica, comenzando en los tiempos de Pedro El Grande. Posteriormente llega a conseguir empleo como Vicebibliotecario de la Academia Real de la Ciencia (Büsching, 1784: 40) y fue acogido posteriormente en calidad de miembro de la corte en Rusia y nombrado caballero de la "Orden imperial del gran príncipe San Vladímir" (Bacmeister, 1787).

Bacmeister, según declaraciones publicadas por sus contemporáneos, inició hacia 1773 la recolección de testimonios lingüísticos con la intención de organizarlos en esquemas clasificatorios. Friedrich Adelung (1768-1843) comenta que su intención no se limitó a la recolección de vocabularios, sino que su esfuerzo también comprendió ejemplos de textos sacados de diferentes lenguas del orbe (Adelung, 1815: 25). Así sentó las bases para emprender estudios lingüístico-comparativos. Se ha afirmado, que esto hizo posible concretar esfuerzos de compilación de listados de palabras procedentes de distintos pueblos, junto con oraciones gramaticalmente complejas en dichas lenguas, lo que "dio a las comparaciones un sólido basamento, con colaboraciones a larga escala" (Plank, 2000: 1340).

La estrategia que emprendió Bacmeister para la obtención de datos lingüísticos susceptibles de comparación, se inició con la publicación de su Nachricht und Bitte wegen einer Sammlung von Sprachproben, aparecida en 1773. La tarea fue descrita en octavilla y media de página, constituyendo ello un manual o instructivo de cómo recoger ejemplos de uso de la lengua, el cual escribió en ruso, francés, latín y alemán. Bacmeister esperaba beneficiarse de la colaboración que podían ofrecerle colegas de las distintas partes de Europa. Deseaba ser exhaustivo y "recolectar traducciones en las distintas lenguas vivientes, 
tanto como pueda recibirlas". Metodológicamente, se topó con la necesidad de imponer una serie de definiciones. Aclara por ejemplo: "nombro como distintas lenguas a todas aquellas que son habladas por dos pueblos distintos, en los cuales el uno entiende la otra no sin ejercicio (dificultad)". Del mismo modo explica que como lenguas vivientes habrá de entenderse también "aquellas que en determinadas ocasiones, como la copta o la griega antigua, se usan en los servicios religiosos". (Bacmeister, 1774: 223).

De esta manera, al realizar la compleja tarea de distribuir manuales para conseguir informaciones sistemáticas para un compendio lingüístico comprensivo, advierte con exigencia: "los trazos, la pronunciación y el significado de cada una de las palabras de la traducción, espero recibirlas y que sean mostradas con exactitud". Indica del mismo modo que "tan pronto como tenga una cantidad considerable de traducciones reunidas", se propone a dar "a conocer las que he reunido, impresas con noticias cortas adjuntas relativas a los pueblos que las hablan" $(1774,224)$. En cuanto a los contenidos que debían de traducirse se encontraban "además de algunos números", también "oraciones cortas, que son entendibles en cualquier parte del mundo". Como ejemplos, Bacmeister señala: "La luna es más grande que una estrella y más pequeña que el sol”, o "ayer por la noche llovió". De esta manera, empleando por igual números ordinarios y oraciones casuales, se distancia de la llana compilación de listados de vocablos y no se limita a "la traducción del conocido Padre Nuestro".

Declara finalmente en su "Noticia", que tiempo atrás, cuando aún tenía su instrucción "como manuscrito, mucho antes de darla a impresión", eruditos como Peter Simon Pallas (1741-1811) y Johann Anton Güldenstädt (1745-1781) ya le habían proporcionado traducciones de la lengua japonesa, lo mismo que ejemplos "de las seis lenguas principales del Cáucaso" $(1774,224)$. Ello puede entenderse como el más antiguo testimonio del que se tiene noticia, con el cual inició la empresa de lograr un esquema tipológico de las lenguas.

En estas tareas se encontraba Bacmeister cuando establece contacto con von Murr. Este último ofrece testimonio de ello en el tomo 6 de su Journal. Señala: "El señor inspector Bacmeister en San Petersburgo me envió el año pasado su 'Noticia y solicitud' impresa en ruso, francés, latín y alemán con motivo de unos ejemplos lingüísticos" (Murr, 1778: 195). Es así como "se cierra el círculo" (Foertsch, 2001: 101) y las relaciones de von Murr con los jesuitas llegarán a servir como fuente de información lingüística para los intereses que por entonces perseguía Bacmeister en Rusia. Ello explica el contexto y motivo del surgimiento de un diccionario bilingüe alemán-tarahumara, escrito posteriormente por el misionero moravo Matthäus Steffel, quien como se mencionó, llevaba ya más de dos décadas de residencia en Europa. Esto explica también que el diccionario se centrara en una lengua originaria del septentrión novohispano y que en su estructura como diccionario incluyera ejemplos gramaticales, uso de números ordinarios, descripción fonética, el Padrenuestro en tarahumara e información etnográfica de la comunidad hablante, así como oraciones traducidas al alemán y latín, basadas en ejemplos que eran comunes a todos los pueblos del orbe.

Como veremos, los esfuerzos de von Murr en el campo de la naciente tipología, si bien pueden considerarse incipientes, tienen el mérito de hallarse bien documentados. Con motivo de la publicación de dos tomos de relaciones documentales jesuíticas, relativas a regiones hispanoamericanas, en el prefacio del primero de los volúmenes, Christoph Gottlieb von Murr comenta: "con las lenguas americanas me he ocupado mucho y he dado frecuentemente pruebas lingüísticas a imprenta en mis Journals de literatura, en mis viajes, impresos por mí en Núremberg en 1785 y en ambas partes de esta obra que 
hoy presento" (von Murr, 1809: X). Continúa señalando además, lo que puede considerarse como el antecedente concreto de todo los esfuerzos tipográfico-lingüísticos realizados hasta ese entonces: "En mi 'Conspectu Bibliothecae glotticae universalis' (1804), clasifiqué las lenguas de América de la forma en la que aquí se ofrece." Indica además que anteriormente "ya había realizado, en 1753, en Altdorf, el boceto de una biblioteca lingüística universal y en Venecia, en 1760, [...] la hice del conocimiento de los más grandes estudiosos de las lenguas en Europa, al ilustre dominico Padre Bonifazio Finetti" (von Murr, 1809: XI).

En torno a esto último señalado por von Murr, puede decirse que la influencia del padre Finetti no fue ciertamente de poca relevancia. El mismo von Murr da a entender, cuatro años antes de haberse encontrado con este religioso en Italia, que Finetti había abierto el camino, publicado la obra Trattato della Lingua ebraica e sue affini, como "prueba de una herramienta lingüística general". Von Murr lamenta que por entonces "para un medio erudito, de los cuales en Venecia (como en cualquier otra ciudad) abundaban, ello no fue casi nada; uno ignoraba a esta dignísima persona, que le era suficiente con hallarse entre sus hermanos de la orden”. Argumenta von Murr que aunque Finetti partió entonces de Venecia rumbo a Fara, población ubicada en las inmediaciones de Gradisca, para vivir en el convento de los dominicos a partir de 1773, lugar donde muere a la edad de 90 años, antes de su deceso (acaecido en 1776), "me escribió muchas cartas enriquecedoras", de las cuales declara que "al igual que mis otros amigos ilustrados", habrían servido para proporcionarle materiales e ideas para integrar su tipología (von Murr, 1809: XI).

Por otra parte, los contactos que von Murr tuvo en Roma en esa la época, incluyen personalidades y letrados como el cardenal Borgia, o el padre agustino Antonio Giorgi, entre otros. Sus relaciones se extendían además a otras personalidades que, como el caso de los jesuitas devueltos a Europa, alguna vez vivieron en Nueva España. Ello comprende, no sólo a misioneros de la Antigua California, como a Benno Ducrué o Wenzelaus Linck, sino sobre todo a Matthäus Steffel. Esa es la razón por la que von Murr presume, en el primer tomo de las relaciones sobre la América española, que "apoyado por la disposición de los misioneros, y de otros valiosos amigos de la Compañía de Jesús, hubiera sido capaz de confeccionar todo un sistema lingüístico americano, de no ser por los tantos achaques, como los que hoy a mis 75 años me lo impiden" (von Murr, 1809: XII).

El agrupamiento de lenguas de pueblos originarios que von Murr efectúa para el continente americano, se inicia con las del polo norte, comenzando por la "esquimal", pasando posteriormente por las ubicadas cada vez más al sur. Tras un largo recuento de grupos y dialectos nativos de Norteamérica, incluye "la lengua de los tarahumaras en la Nueva Vizcaya" como perteneciente a la rama superior de las lenguas mexicanas. Esto, publicado como preámbulo a la obra en que se incluye el diccionario de Steffel en 1809, ya había sido clasificado, en su tipología de 1804; es decir, cinco años antes.

En este punto de nuestra reconstrucción de hechos, se hace visible cómo von Murr tendió puentes entre los intereses de Ludwig Christian Bacmeister en Rusia, con las aportaciones de algunos miembros de la Compañía de Jesús, que tiempo atrás habían misionado en el Nuevo Mundo. Se puede ahora comprender con más exactitud, el significado de las palabras que Steffel plasma en su carta del 28 de marzo de 1791, signada en Brno (o Brünn, en alemán, como prefiere utilizar el editor). En ella comunica Steffel a von Murr: "Debido a que no he tenido el ejercicio de esta lengua por más de 20 años, encontré necesario, tanto a su solicitud como a mis propias palabras, mucho que dedicarles, sometiendo a la prueba de un amigo versado de esta lengua mis traducciones de las oraciones de Bacmeister; de tal manera que", añade 
el misionero, "tengo la esperanza, que será tanto esta traducción tarahumara como el resto del diccionario, no desconocida para los anteriormente versados en esta lengua, ni a los misioneros que aún viven en Alemania, mis compañeros, si es que debe llegar a sus manos, de quienes quedo de toda consideración" (Steffel, 1809: 295).

\section{El diccionario tarahumara en la obra de Adelung y Humboldt}

El Tarahumarisches Wörterbuch puede ser visto así, como un suministro de información lingüística en dos sentidos: sirve por un lado como recurso documental básico para fundamentar las primeras iniciativas de clasificación tipológica de 'lenguas mexicanas', como sucedió para von Murr gracias a la muestra lingüística que Steffel elabora para Bacmeister. Pero, por otro lado, yendo un paso más allá, Steffel concibe el diccionario como un instrumento de descripción general de los "usos y costumbres de la etnia", dirigido a la sociedad ilustrada europea en la que le tocó vivir. Ese es el sentido original de las preguntas que plantea en el prefacio de su obra: "Quizá pueda uno decir: ¿para qué tal diccionario? ¿Quién sacará utilidad de este esfuerzo mío?". A lo que él mismo responde, que aun cuando una cosa pueda ser de escaza utilidad, no debe considerársele como nula. Afirma que no es de menospreciarse que en alguna ocasión se pueda brindar con él un uso práctico. Quizá puede suceder, sugiere, "que en otro siglo, quizá otros europeos, rusos o tal vez alemanes, encuentren traspasando el mar ilimitado una entrada libre y sin restricciones en este continente lleno de contrastes" (Steffel, 1809: 296).

El diccionario tarahumara, con la abundancia de observaciones etnográficas sobre la vida y costumbres de los naturales, misma que detalla en sus ilustrativas entradas (Brenscheidt, 2014), no sólo pretende dar cuenta de la constitución sintáctica y gramatical características de la lengua, en el sentido que Bacmeister lo solicitaba, sino que se considera por parte de su autor como algo utilitario. Afirma en la introducción que los “viajeros no lo encontrarán como lastre sino, si es que deben llegar hasta la Tarahumara, será un buen intérprete en esta nación y en la adquisición del lenguaje un buen maestro de la lengua”.

Es por el contrario en la sección final, en el cierre o conclusión posterior a la parte tarahumara-alemán del diccionario, misma que el editor intitula: "Muestra lingüística tarahumara", el lugar donde Steffel evidencia tener conocimiento del proyecto tipológico que movía a los solicitantes de su obra lexicográfica. El misionero señala: "El Sr. Bacmeister en San Petersburgo tuvo ya el año de 1773 el deseo de recibir las fórmulas elaboradas por él en diferentes lenguas", a lo que agrega que ya fueron impresas "algunas de ellas del Sr. von Murr, Journal, parte VI, p. 195 y parte IX, p. 96". Steffel concluye entonces: "Yo he traducido también estas fórmulas en mi lengua tarahumara" y "debido a que confeccioné mi diccionario tarahumara al alemán, quiero transcribir estas fórmulas en latín, alemán y tarahumara" (Steffel, 1809:371). En su totalidad, el trabajo de Steffel publicado por von Murr en 1809, incluye 22 oraciones que transcribe en los tres idiomas anteriormente descritos, a lo cual añade "la oración del señor" o "El Padrenuestro" en lengua rarámuri.

7- Vid. La expresión en alemán de Steffel, escrita en caracteres góticos, reza: "Man wird zwar fagen: zu was ein folches Woerterbuch? Wem wird diefe meine Bemühung einen Nutzen fchaffen?

8- Vid. A modo de ejemplo se utiliza en los paratextos del diccionario lo solicitado por Bacmeister. Primero en latín: Luna major est quam stella et minor quam sol; después en alemán: 'Der Mond ist größer als ein Stern, und kleiner als die Sonne', y 
Así, con lo señalado hasta aquí, podemos proponer una respuesta a la pregunta que Steffel planteara, relativa a quién podría sacar provecho de su libro. Se beneficiaron, en primer lugar y de forma privilegiada, los primeros esfuerzos de tipología lingüística a los que los vocablos y oraciones en tarahumara sirvieron de recurso informativo para agrupar parte de la familia yutoazteca; fueron particularmente útiles las oraciones y los paratextos. Del mismo modo, se benefició del diccionario la primera clasificación (inexacta y limitada si se quiere), elaborada por Christoph Gottlieb von Murr. Este personaje, a juzgar por las investigaciones posteriores realizadas en los archivos personales de Hartwig Ludwig Christian Bacmeister (Foertsch, 2001: 101), no habría enviado nunca a San Petersburgo las pruebas lingüísticas elaboradas por Steffel, conformándose con darlas a conocer a través de las publicaciones especializadas que editaba y con las dos partes de las Noticias sacadas a la luz en 1809 en Halle.

Tanto von Murr -quien tuvo mayor protagonismo-, como Bacmeister, fueron incapaces de elaborar una propuesta tipológica universal en cuanto a les fue imposible constituir una base documental extensa para su tipología; por lo menos no lo lograron de manera que fuera reconocida entre los contemporáneos. Bacmeister reelaboró su proyecto tipológico en 1784, para abandonarlo de nuevo sin éxito cinco años más tarde (Foertsch, 2001: 102). Queda claro sin embargo, que al definir con eficiencia las bases comparativas usando oraciones y no vocablos, privilegiando la dimensión gramatical para usarla con fines tipológicos, Bacmeister nutrió el esfuerzo iniciado previamente por von Murr. Finalmente, en segundo lugar, se vieron beneficiados con la obra de Steffel los sucesores de posteriores esfuerzos lingüísticotipológicos o estudios de corte comparativo.

El primero de ellos fue Johann Christoph Adelung, quien con su Mithridates ofrece en 1812, "una información lingüística general", empleando para ello, como unidad de análisis el Padrenuestro recopilado en más de quinientas lenguas. En su tercer volumen, dedica un apartado especial al tarahumara, explicando sus personas, formación de sustantivos según casos, adjetivos, números ordinarios, pronombres personales, verbos, preposiciones, formación de palabras, etcétera. Retoma del diccionario de Steffel las "pruebas lingüísticas" y el Pater Noster y lo compara con el cora (Adelung, 1812: 146). Debido a la diligencia que Steffel tuvo, de corroborar las informaciones que incluye en su diccionario, Adelung otorga al misionero "la completa seguridad de la correcta presentación de esa lengua" (1812: 142).

El segundo beneficiado es Wilhelm von Humboldt, quien tras mudarse a su villa de Tegel, hacia 1827, inicia con estudios lingüísticos comprensivos, empleando textos proporcionados por sus colegas, recopilados en viajes y sobre todo los reunidos por su hermano Alejandro. En esta tarea resultarán de gran ayuda los aportes de su secretario, Eduard Buschmann, en cuyo fondo se preserva hasta hoy la transcripción de una gramática tarahumara escrita a mano por el mayor de los dos hermanos (Mueller-Vollmer, 1993: 356).

De hecho, Humboldt emprende esfuerzos de unificación de gramáticas americanas, y particularmente la elaboración de una "mexicana, que involucró lenguas como la otomí, maya, mixteca, totonaca, cora y tarahumara" (Sakel y Stolz, 2012: 25). Se ha propuesto también, que para el esfuerzo lingüístico que representó su libro, intitulado Kosmos, una de sus máximas obras, Humboldt se allegó textos que le sirvieron para comprender la raíz 'mexicana', teniendo acceso también a la gramática tarahumara de fray Miguel de Tellechea (1826) y a los apuntes de la lengua mexicana de fray Bernardino Sahagún (Reutter, 2011:239). Se ha afirmado por último, que para la confección de su Mexikanische

finalmente en tarahumara: Maitsàca guelubé húcu mapuíeri sopolí, khutabé putsé mapujeri taicà (Steffel, 1809, 374). 
Grammatik, Wilhelm echó, además, mano de documentos jesuíticos del norte de la Nueva España, entre los que se hallaban lo publicado por los misioneros Bägert, Eckert, Bayer, Brewer, Dobrizhoffer, Ducrue, Och y Steffel (Reutter, 2011: 251). El Diccionario de la lengua mexicana de Humboldt, dedicado al náhualt, también emplea como recurso documental los ejemplos extraídos del libro de Steffel (Buschmann y Humboldt, 2000: 237).

Para finalizar esta reconstrucción del contexto cultural en que obtiene significado internacional el diccionario bilingüe de Steffel, debe decirse que los trabajos de compilación impresos pot von Murr fueron descritos, después de su muerte, con igual simpatía que escepticismo. Personalidades cercanas a él en intereses, tanto intelectuales como materiales (como fue el caso de Johann Ferdinand Roth), lo catalogaron por entonces "como uno de los primeros eruditos lingüistas de su época, aun cuando sus escritos de vez en cuando carecieran de agudeza y se extrañara en ellos la crítica”. Añade, para suavizar sus reprensiones: "[...] en algo en que sí coinciden sus adversarios y amigos es en la fabulosa ciencia, en el raro conocimiento de las lenguas de oriente y occidente, así como en el incansable estudio de las ciencias humanas que con ellas iluminó" (Roth, 1811: XVI).

Cerrando finalmente con el diccionario alemán-tarahumara de Matthäus Steffel, poco puede decirse de la suerte que por último corrió el manuscrito base del diccionario tarahumara, por lo menos el de la versión que Christoph Gottlieb von Murr recibiera a finales del XVIII de manos del misionero. Se sabe solamente lo declarado por Murr, quien hablando de sus compilaciones de textos lingüísticos llegó a afirmar: "dejé en 1807 todo lo que puse en papel, al señor profesor Johann Severin Vater en Halle" (1809: XI).

Los datos más cercanos a nuestro presente los hemos encontrado en un documento de relación que Roth publica en alemán, con motivo de tener que subastar la biblioteca de von Murr tras su muerte (1814: 17). El diccionario de Steffel, identificado como manuscrito, aparece en la lista de venta con el número 258, con una extensión de 103 páginas y en formato a cuarto de página. La subasta se planeó llevarla a cabo el 14 de septiembre de 1814 en la ciudad de Núremberg, y para la fecha de la publicación del catálogo de obras, había al menos 17 compradores interesados en participar en la adquisición de los materiales.

\section{Conclusión}

Habiendo sido expuesta la fragmentaria información histórica que puede reunirse hasta nuestros días, la cual permite una introspección limitada al contexto de la época, se hacen visibles circunstancias que fortalecen la hipótesis de que el diccionario de Steffel sirvió a los esfuerzos tipológicos de la época.

De esta suerte, pueden comprenderse algunos aspectos del entorno intelectual y de la forma en que se fundamentaron las primeras categorizaciones tipológico-lingüísticas con base pragmática; es decir, sustentada en información obtenida de hablantes en campo. Ellas se desarrollaron y se potenciaron durante una etapa específica de la civilización europea; a saber, durante la Ilustración y el colonialismo, coincidentes ambos a finales de la segunda mitad del siglo XVIII.

Debido a su condición como fuente de información racional, sistemática y proveniente de una lengua originaria en uso, tanto el diccionario como las pruebas lingüísticas que en él se incluyen, comunican al lector cierta admiración por los hablantes y la condición natural en que habitan. Admira de los tarahumaras la sana y ruda disposición de su cuerpo, del complejo arte de la lengua que da sustento a su bárbara 
pero prístina sencillez. Algo que intelectuales y filósofos como Rousseau, en obras como Lettres persanes (1721), habían puesto, con la metáfora del "buen salvaje", completamente de moda por toda Europa.

La elaboración de un diccionario bilingüe, que a la vez fue fuente informativa, como el aquí estudiado, contribuyó a la expansión del conocimiento de los pueblos, tal y como lo requería el sistema occidental mundial. Éste acelerará el ritmo de intercambio con el Nuevo Mundo un par de décadas después, impulsado por la Revolución Industrial y la movilidad transcontinental propiciada por el uso del vapor a principios del siglo XIX.

Los esfuerzos de clasificación lingüística de la época fueron iniciativas nutridas por relaciones epistolares, obtenidas de campo y circuladas a escala global, enviadas a Europa a través del Atlántico. Con ello se vincularon pueblos originarios americanos, agentes coloniales, coleccionistas eruditos, empleados en las cortes reales europeas; así como también editores y lectores interesados en conocer peculiaridades lingüísticas de súbditos de otros reinos y geografías del orbe.

Respecto al espacio cultural de habla alemana que aquí ha sido analizado, el diccionario alemán-tarahumara de Matthäus Steffel, empleó pruebas lingüísticas de las sugeridas por Bacmeister. Como tal, el diccionario impreso nunca llegó a las manos de éste último, quien muere en 1806; es decir, tres años antes de que el diccionario saliera de imprenta (Winter y Harosh, 1983: 123). No obstante, su recepción como obra de cierto valor lingüístico se corrobora en Adelung, Severin y Humboldt. Ello muestra cómo el Tarahumarisches Wörterbuch fue de utilidad para nutrir el debate ilustrado, sostenido por estudiosos en las diferentes cortes, quienes por entonces emprendieron serios (aunque limitados) esfuerzos de clasificación tipológica.

A diferencia de Leibniz, cuyas reflexiones en torno al posible origen de la diversidad lingüística se mantuvieron siempre en el estricto plano especulativo, después de los esfuerzos de esta primera generación de letrados (a la que pertenecieron von Murr y Bacmeister), se desarrollaron iniciativas de clasificación más comprensivas, centradas en la recolección de información en ultramar y obtenidas de la experiencia personal de agentes coloniales que estuvieron en contacto con lenguas nativas. Ejemplo de ello será, en la Nueva España, el trabajo de Lorenzo de Hervás y Panduro (1735-1801). Este personaje, a diferencia de los autores alemanes aquí citados, conseguirá avanzar en dos aspectos decisivos: en superar, por un lado la metafísica de presuponer la existencia de una lingua matriz; así como proceder por otra parte, de forma metódica, para comparar distintas lenguas, entre ellas muchas continentales, tomando a la oración y no al vocablo como unidad estable (criterio empleado ya por Bacmeister). En otras palabras, los esfuerzos no se habrán de enfocar más en contrastar vocabularios, sino que se pondrá interés sobre todo en la gramática y la "fonación" (Foertsch 2001: 130; Hervás y Panduro 1800: 11).

La fascinación que movió a von Murr y Bacmeister por elaborar un arreglo tipológico universal, seguirá contagiando esfuerzos por categorizar las lenguas existentes en las regiones del orbe y sumará a la postre iniciativas como las de Adelung y Severin Vater. La propia Catalina La Grande de Rusia establecerá contacto con las autoridades imperiales de Europa para que sus eruditos continúen la tarea de elaborar la clasificación que Bacmeister dejará inconclusa. Ella misma escribirá y solicitará a Carlos III, listados de información lingüística con dicho propósito. Sus gestiones llevaron a la autoridad monárquica española en 1787, a pedir al mando virreinal en Buenos Aires, informaciones que el sucesor de Bacmeister en San Petersburgo, Peter Simon Pallas, habrá de emplear para dar fin a la obra de su coterráneo (Larrucea, 1986: 214).

Por último, se ha señalado que "a finales del siglo XVIII, existieron informaciones y luminarias en relación con la sistematización del reino del lenguaje, las cuales fueron difíciles de pasar desapercibidas 
en el escenario intelectual de la Europa ilustrada" (Plank, 2001: 1412). Con los elementos aquí mostrados, podemos agregar que se realizaron muchos esfuerzos de sistematización, que a pesar de basarse en la obtención y corroboración de datos lingüísticos obtenidos por agentes coloniales que trabajaron sobre el terreno, no llegaron a concluirse, ni tuvieron en la época el reconocimiento merecido.

Ha sido propuesto, que durante el siglo XIX, la lingüística alemana "se estableció por sí misma como ciencia reflexionando acerca de las lenguas indoeuropeas, su origen común y su desarrollo, y ello principalmente sobre la base de un análisis fonético-estructural". En esa tarea, una metáfora dominará el campo de los estudios lingüísticos. Ésta se adjudica a August Schleicher (1821-1868), quien propuso comprender el lenguaje cual 'organismo' (Nerlich y Clarke, 1996: 25). Los lingüistas se moverán así al estudio de la anatomía de la lengua, de su estructura gramatical y a la comprensión de las leyes de su consolidación, desarrollo y desaparición. Como en la biología, el lenguaje será "visto como un fenómeno que vive y muere, crece y decae, de acuerdo con sus leyes constitutivas, independientemente de los hablantes".

Valga por último afirmar, que el diccionario alemán-tarahumara de Matthäus Steffel, puesto en su contexto de surgimiento y mostrado a la luz de las relaciones intelectuales que le dieron visibilidad en Europa, permite conocer la dimensión global y epistemológica a la que, queriendo o no, contribuyeron los misioneros ignacianos, distribuidos desde Filipinas a Nueva España; labor que después de la Reforma, permitió renovar la tarea de universalización católica, algo que otras contribuciones académicas han preferido llamar proyecto de "catolicismo global de salvación" jesuita (Clossey, 2008: 257).

La forma y contenido del diccionario como constructo lingüístico, sigue permitiendo al día de hoy, adentrarnos al fascinante ( $\mathrm{y}$ aún poco conocido) universo simbólico rarámuri. Nuestro interés fue fortalecer, la hipótesis de que, siendo útil para von Murr, Adelung, Severin y Humboldt, lo es también para nosotros, al ofrecernos una puerta de entrada que permite conocer la lenta pero constante conformación de la disciplina lingüística, la cual que comenzó a definir por entonces campos temáticos como la tipología.

\section{Referencias}

Aarsleff, Hans. 1974. The Tradition of Condillac. En Studies in the History of Linguistics, editado por Dell, H. Hymes. Bloomington: Indiana University Press, 93-156.

Adelung, Friedrich. 1815. Catherinens der Grosse Verdinste um die Vergleichende Sprachkunde. Sankt Petersburg: Drechsler.

Bacmeister, Hartwich. 1772-1787. Russische Bibliothek, zur Kenntnis des gegenwärtigen Zustandes der Literatur in Russland. Tomo 11. Leipzig: Johann Friedrich Hartknoch.

Bayly, Christopher. 2004. The birth of the modern world, 1780-1914. Malden: Blackwell.

BS (Bayerische Staatsbibliothek). 1796. Brief von Johann Christoph Adelung an Christoph Gottlieb von Murr, Dresden. DE-611-HS-47243. Múnich: 1976.

Bayly, Christopher. 1794. Brief von Friedrich Schiller an Christoph Gottlieb von Murr, Jena. DE-611HS-77565. Múnich: Bayrische Staatsbibliothek.

Borja, Galaxis. 2011. Die jesuitische Berichterstattung über die Neue Welt. Zur Veröffentlichungs-, Verbreitung- und Rezeptionsgeschichte jesuitischer Americana auf dem deutschen Buchmarkt im Zeitalter der Aufklärung. Göttingen: Vandenhoeck y Ruprecht. 
Brenscheidt, Diana. 2007. "Precursor de Etnografía: Matthäus Steffel y su 'tarahumarisches Wörterbuch"'. En Intercambios, actores, enfoques. Pasajes de la historia latinoamericana desde una perspectiva global, coordinado por Grageda, Aarón. Hermosillo: Universidad de Sonora 47-60.

Brumm, María. 2007. "El diccionario tarahumara-alemán de Matthäus Steffel como fuente de conocimiento de la lengua y la cultura tarahumaras". En Desde los confines de los imperios ibéricos. Los jesuitas de habla alemana en las misiones americanas, editado por Kohut, Karl, Torales Pacheco y María Cristina. Madrid: Iberoamericana, 395-406.

Büsching, Anton. 1784. Wöchentliche Nachrichten von neuen Landcharten, geographischen. T. 12, Berlin: Haude und Spener.

Buschmann, Eduard y Wilhem von Humboldt. 2000. Wörterbuch der mexikanischen Sprache. Tomo 2. Paderborn: F. Schöningh.

Carhart, Michael. 2007. The science of culture in enlightenment germany. Harvard: Harvard University Press. Clossey, Luke. 2008. Salvation and globalization in early Jesuits missions. Cambridge: Cambride University Press.

Díaz, Claudia. 2010. Descripción y generalidades lexicográficas del diccionario alemán-tarahumara de Matthäus Steffel. Tesis de maestría. Hermosillo: Universidad de Sonora.

Estrada, Zarina y Aarón Grageda. 2017. La historiografía lingüística como ejercicio interdisciplinar compartido: la obra de Matthäus Steffel. Actas de la Sociedad Mexicana de Historiografía Lingüística, 187-207. Foertsch, Henrike. 2001. Missionmaterialien und die Entdeckung amerikanischer Sprachen. En Sammeln, Vernetzen, Auswerten. Missionare und ihr Beitrag zum Wandeln europäischer Weltsicht. Editado por Wendt, Reinhard. Tübingen: Gunter Narr, 75-130.

Frängsmyr, Tore, John Heilbron y Robin Rider. 1990. The quantifying spirit in the 18th century. Berkeley: University of California Press.

Gardt, Andreas. 1999. Geschichte der Sprachwissenschaft in Deutschland. Vom Mittelalter bis in das 20. Jahrhundert. Berlin: De Gruyter.

Gascoine, John. 2003. Joseph Banks and the English Enlightenment: Useful Knowledge and Polite Culture. Cambridge: Cambridge University Press.

González, Luis. 1995. Thomas de Guadalaxaja (1648-1720), misionero de la tarahumara, historiador, lingüista y pacificador. Estudios de historia novohispana 15 (1995): 9-34.

Hausberger, Bernd. 1995. Jesuiten aus Mitteleuropa im kolonialen Mexiko: eine Bio-Bibliographie. Wien: Verlag für Geschichte und Politik.

Hervás y Panduro, Lorenzo. 1800. Catálogo de las lenguas de las naciones conocidas y numeración, división, y clases de estas según la diversidad de sus idiomas y dialectos [...]. Volumen 1. Madrid: Imprenta de la Administración del Real Arbitrio de Beneficiencia.

Jürgensen, Renate. 2002. Bibliotheca Norica. Tomo 2. Wiesbaden: Herrassowitz Verlag.

Kendon, Adam. 2013. History of the study of gesture. En The Oxford Handbook of the History of Linguistics. Editado por Allan Keith. Oxford: Oxford University Press, 71-90.

Křížová, Markéta. 2013. Misiones jesuitas y la imagen de América en Europa en los siglos XVII y XVIII. En Virreinatos II. Editado por Lilian von der Walde y Mariel Reynoso. Ciudad de México: Editorial Grupo Destiempos, 120-138. 
Larrucea, Consuelo. 1986. José Celestino Mutis (1732-1808) and the Report on American Languages ordered by Charles III of Spain for Catherine The Great of Russia. The History of Linguistics in Spain, 11(2): 213-229.

Lauch, Annelies. 1969. Wissenschaft und kulturelle Beziehungen in der russischen Aufklärung: zum Wirken H. L. Ch. Bacmeisters. Berlin: Akademie-Verlag.

Lifschitz, Avi. 2012. Language and enlightenment: The Berlin debates of the eighteenth century. Oxford: Oxford Universty Press.

Merrill, William. 2007. La obra lingüística del padre Matthäus Steffel S.J. En Desde los confines de los imperios ibéricos. Los jesuitas de habla alemana en las misiones americanas. Editado por Karl Kohut y María Torales. Madrid: Iberoamericana, 409-441.

Mueller-Vollmer, Kurt. 1886. Wilhelm von Humboldts Sprachwissenschaft. Paderborn: F. Schöningh, 409-441. Mummenhoff, Ernst. Allgemaine deutsche Biographie. Tomo 23. Leipzig: Verlag von Dunker und Hublot, 76-80. Nerlich, Brigitte y David Clarke. 1996. Language, action, and context: The early history of pragmatics in Europe and America, 1780-1930. Amsterdam y Philadelphia: John Benjamins.

Och, Joseph. 1809. Joseph Ochs, Glaubenpredigers der G.J. in Neumexiko, Nachrichten von seinen Reisen nach dem spanischen Amerika, seinen dortigen Aufenthalte vom Jahr 1754 bis 1767. En Nachrichten von verschiedenen Länder des Spanischen Amerika, aus eingenhändigen Auffassen einige Missionare der Gesellschaft Jesu. Tomo. 1. Editado por Murr, Gottlieb Christoph. Halle: Johann Christian Hendel, 3-298. Osterhammel, Jürgen. 2014. The transformation of the world: A global history of the nineteenth century. Princeton: Princeton University Press.

Pedersen, Holger. 1983. A glance at the history of linguistics: With particular regard to the Historical Study of Phonology. Amsterdam: John Benjamins.

Plank, Frans. 2001. Typology by the End of 18th Century. En History of the language sciences: an international handbook on the evolution of the study of language from beginnigs to the present, v. 2. Editado por Auroux, Sylvain. Berlin: de Gruyter, 1339-1413.

Reutter, Georg. 2011. Kosmos der Sprache: Wilhelm von Humboldts linguistisches System. Paderborn: F. Schöningh.

Rodríguez, Abel.2010. Gramática Tarahumara, (edición crítica a la Gramática Tarahumara de Thomas de Guadalaxara publicada en 1683), Ciudad de México: UACJ, UACH, CONACULTA, ICHICULT.

Roth, Johann. 1811. Catalogus Librorum quos V.C. Christophorus Theophilus de Murr [...], Noringa: Libropolio Licherneriano.

Roth, Johann. 1814. Verzeichnis des Restes der Murr'schen Bibliothek, welcher am 19. September 1814 und folgenden Tagen zu Nürnberg, öffentlich versteigert werden soll. Nürnberg: s.i.

Sakel, Jeanette y Thomas Stolz. 2012. Amerindiana: Neue Perspektiven auf die indigene Sprachen Amerikas. Berlin: Akademie-Verlag.

Salmon, Paul. 1995. Origin of language debate in eighteen century. En Concise history of the language sciences: From sumerians to the cognitivist. Editado por E. Koerner y R. Asher. New York: Elsevier, 184-187. SH, (Stadtarchiv Halle). 1773. Schreiben von Christoph Gottlieb v. Murr [Torrubia: Naturgeschichte Spanien], Signatur DE-611-HS-2281799. Halle: Stadtarchiv Halle.

Steffel, Matthäus. 1809. Tarahumarisches Wörterbuch, nebst einigen Nachrichten von den Sitten und Gebrauchen der Tarahumaren, in Neu-Biscaya, in der Audiencia Guadalaxara, im Vice-Königreiche Alt- 
Mexico, oder Neu-Spanien. En Nachrichten von verschiedenen Länder des Spanischen Amerika, aus eingenhändigen Auffassen einige Missionare der Gesellschaft Jesu. Tomo. 1. Editado por Christoph Gottlieb von Murr. Halle: Johann Christian Hendel, 293-374.

Von Murr, Christoph. S/F. Acht und zwanzig Briefe über die Aufhebung des Jesuitensordens. S. 1: s.i. Von Murr, Christoph. 1789. Journal zur Kunstgeschichte und zur allgemeinen Litteratur. Tomo 17. Núremberg: Johann Eberhard Geb.

Von Murr, Christoph. 1799. Neues Journal zur Litteratur und Kunstgeschichte. Tomo 2. Leipzig: s.i. UM (Universitätsbibliothek München). 1788. Brief von Johann Gottfried von an Christoph Gottlieb von Murr, Weimar, Signatur 2, Cod. Ms.: 54. Múnich: Universitätsbibliothek München.

Winter, Eduard y Günther Jarosch. 1983. Wegbreiter der deutsch-slawischen Wechselseitigkeit. Berlin: Akademie-Verlag. 